\title{
PENGARUH HAFALAN AL-QURAN TERHADAP PRESTASI BELAJAR PADA MATA PELAJARAN ALQURAN HADIST KELAS XI MIA.1 MAN 2 PAREPARE
}

\author{
Mirhanah \\ Guru MAN 2 Kota Parepare \\ Email:mirhanah@gmail.com
}

\begin{abstract}
The research was conducted in framework to determine the influence of Al Quran memorized to student learning achievement of XI natural science class MAN 2 Parepare. Learning achievement is a student's attainment result from the learning is got at school in period which have been settled at Al Quran hadist lesson. While Al Quran hadist is the lesson which is inside it learn about Al Quran verses and hadist texts in order to comprehend Al Quran and Hadist content. This research was taken place in MAN 2 Parepare began in April to june with research sample was all students of XI MIA 1 class counted 23 persons. Data was taken by inquiry got from students. Method which was used was linear regretion analysis caorrelation product moment significant level 5\%. Research of processing data was showed $r$ count equal to 0,6270 with degree of freedom $=23-2=21$ significant level $5 \%$ resulted table 0,3932 it means hypothesis nothing ( $\mathrm{Ho})$ is rejected and alternative hypothesis $(\mathrm{Ha})$ is accepted means there is influence Al Quran memorized to student's learning achievement.
\end{abstract}

Keywords: Quran Recitation, Learning achievement, Quran Hadits

\section{ABSTRAK}

Penelitian dilakukan dalam rangka mengetahui pengaruh hafalan Alquran terhadap prestasi belajar peserta didikdi Kelas XI Ilmu Pengetahuan Alam (IPA) MAN 2 Parepare. Prestasi belajar merupakan suatu hasil pencapaian peserta didikdari pembelajaran yang didapatkan di sekolah pada periode yang telah ditetapkan pada mata pelajaran Alquran Hadits. Sedangkan mata pelajaran Alquran Hadist adalah mata pelajaran yang didalamnya mempelajari tentang ayat-ayat Alquran dan teks-teks Hadits guna memahami kandungan dari Alquran dan Hadist tersebut. 
Penelitian ini dilaksanakan di MAN 2 Parepare pada bulan April sampai dengan Juni dengan sampel dalam penelitian ini adalah keseluruhan peserta didikKelas XI MIA.1 sebanyak 23 orang. Data didapat melalui angket yang diperoleh dari siswa. Metode yang digunakan adalah analisis regresi linier korelasi product moment tingkat taraf signifikansi 5\%. Hasil olah data menunjukkan $r$ hitung sebesar 0,6270 dengan degree of freedom $=23-2=$ 21 taraf signifikansi 5\% dihasilkanr tabel 0,3932 yang berarti $\mathrm{r}$ hitung lebih besar dari $r$ tabel $(0,6270$ 0,3932). Artinya hipotesis nihil (H0) ditolak dan hipotesis alternatif $(\mathrm{Ha})$ diterima yang berarti terdapat pengaruh hafalan Alquran terhadap prestasi belajar siswa.

\section{Kata Kunci: Hapalan Alquran, Prestasi belajar, Quran Hadits}

\section{PENDAHULUAN}

\section{Latar Belakang}

MAN 2 Parepare sebagai salah satu wadah pendidikan, membuka peluang untuk masyarakat dalam bermujahadah untuk menuntut ilmu. Melalui muatan kurikulum madrasah yang memasukkan mata pelajaran Alquran Hadits sebagai bagian dari mata pelajaran, menjadi supplement bagi peserta didikyang berminat belajar menghafal ayat-ayat Alquran. Menghafal Alquran merupakan bagian dari ibadah yang dicontohkan oleh Rasulallah S.A.W. Hal tersebut dilakukan pula oleh para sahabat dimana mereka menghafalkan ayat-ayat Alquran langsung dari Rasulullah S.A.W. setelah wahyu tersebut turun. Abdul Qoyyum menyatakan bahwa menghafal adalah upaya menyampaikan hasil dalam fikiran, setelah mengingat sehingga mampu menghadirkan ilmu itu kapan pun dikehendaki. ${ }^{1}$

Alquran sebagai sumber utama umat Islam menjalankan syariat agamanya, menjadi tuntutan untuk selalu dikaji dan dipahami. Selain untuk dibaca dan didengarkan atau diperdengarkan, serta untuk diperhatikan atau direnungkan dan kemudian untuk diaktualisasikan secara aplikatif sebagai

\footnotetext{
${ }^{1}$ Abdul Qoyyum bin Muhammad bin Nashir As Sahaibani. 2009. Keajaiban Hafalan, Bimbingan bagi yang Ingin Menghafal Al Qur'an. Jogjakarta: Pustaka Al Haura. h. 12
} 
tujuan utamanya, ${ }^{2}$ Alquran dapat pula menjadi sarana untuk meningkatkan kecerdasan intelektual sekaligus kecerdasan spiritual seseorang. ${ }^{3}$ Allah berfirman dalam QS. Al-A'la: 6, sebagai berikut:

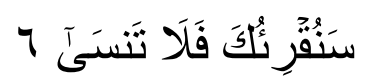

Terjemahnya:

"Kami akan membacakan (Alquran) kepadamu (Muhammad) maka kamu tidak akan lupa".

Ayat tersebut mengisyaratkan bahwa setiap hafalan diawali dengan bacaan yang diulang-ulangi dan sekaligus diamalkan. Pendidikan Islam yang bermanfaat jika ilmu pengetahuan yang dipelajari dapat dikuasai selanjutnya diamalkan dan berimplikasi kepada kepribadian peserta didik. Hal tersebut menjadi sasaran pendidikan Islam yakni memiliki implikasi positif pada ranah kognitif, afektif, dan psikomotorik pada diri peserta didik setelah mengikuti pembelajaran. ${ }^{5}$ Berkembangnya ketiga ranah tersebut setelah mengikuti pembelajaran merupakan prestasi belajar yang diraih peserta didik. Prestasi belajar ialah hasil pencapaian yang diperoleh seorang pelajar setelah mengikuti ujian dalam suatu pelajaran tertentu. Hasil belajar digunakan untuk melihat bagaimana perkembangan yang diraih peserta didikselama waktu tertentu. ${ }^{6}$

Unang Wahidin mengatakan, bahwa hasil belajar bisa juga ditunjukan dengan adanya perubahan di dalam diri orang yang belajar dimana terdapat perbedaan keadaan antara sebelum dan sesudah melakukan kegiatan belajar. Pengertian tersebut memberi petunjuk bahwa keberhasilan belajar dapat

${ }^{2}$ Lihat AAR. Maya. 2014. Perspektif Al-Qur'an Tentang Konsep Al-Tadabur. AlTadabbur: Jurnal Ilmu Al-Qur'an dan Tafsir, 01(01). h. 2.

${ }^{3}$ Lihat Abdul Halik, Ahdar, Suredah, "The Influence of Emotional and Spiritual Intelligence of Educator towards Learning Quality Improvement", Proceeding $5^{\text {th }}$ International Conference on Applied Sciences, Arts and Social, and Community Development in the ASEAN 2018, University of the Philippines, Manila, July 19-20, 2018.

${ }^{4}$ Kementerian Agama Republik Indonesia. 2013. Al Qur'an dan Terjemahnya. Bandung: Nuurun 'Aalim. h. 591

${ }^{5}$ St. Wardah Hanafie Das, Abdul Halik, Zulfianah, Muh Naim, "Strategies of Islamic Education Teachers to Increase Students' Interest in Learning and Practicing in State Junior High School (SMPN) 1 Lanrisang, Pinrang", Madania, Vol. 22, No. 2, Desember 2018, h. 253-264.

6 Agoes Dariyo. 2013. Dasar-Dasar Pedagogi Modern. Jakarta: PT Indeks Permata Puri Media. h. 90 
diukur dengan adanya perubahan, baik pada aspek kognitif, apektif maupun psikomotorik. $^{7}$

Hadits menurut ulama ushul sama artinya dengan sunnah qauliyah. Sunnah lebih umum dari hadits karena juga mencakup perbuatan dan taqrir Nabi yang menjadi dalil hukum syara. Hadits atau sunnah meliputi segala perkataan, perbuatan, dan taqrir Nabi, baik yang mencakup hukum maupun tidak. ${ }^{8}$ Selain itu, hadits sebagai sumber hukum dari agama Islam yang ke-2 menjadi penambah bagi para pembaca Alquran untuk memperoleh pengetahuan yang lengkap terkait ayat-ayat yang terdapat di dalam Alquran namun belum diketahui tafsir secara jelasnya. pelajaran hadits dikolaborasikan dengan Alquran sehingga menjadi mata pelajaran Alquran Hadits.

Hadits merupakan sumber hukum kedua bagi umat islam, hal ini dijelaskan dalam QS. An-Nisa: 59, sebagai berikut:

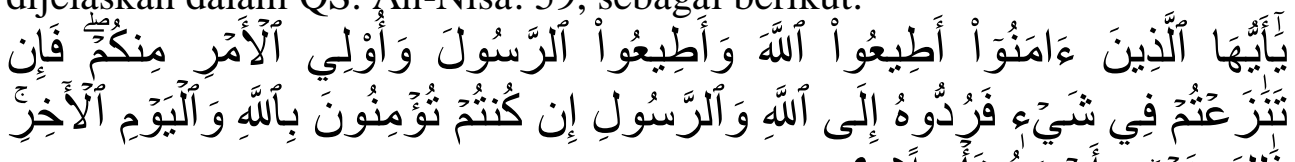

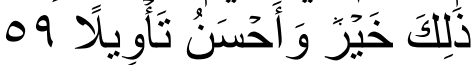

Terjemahnya:

Hai orang-orang yang beriman, taatilah Allah dan taatilah Rasul (Nya), dan ulil amri di antara kamu. Kemudian jika kamu berlainan pendapat tentang sesuatu, maka kembalikanlah ia kepada Allah (Al Quran) dan Rasul (sunnahnya), jika kamu benar-benar beriman kepada Allah dan hari kemudian. Yang demikian itu lebih utama (bagimu) dan lebih baik akibatnya. ${ }^{9}$

Untuk program hafalan Alquran maka setiap peserta didikdiberikan target untuk menghafal beberapa juz dari Alquran selama menempuh pendidikan. Target tersebut tergantung dari kemampuan peserta didik dalam menghafal. Akan tetapi, MAN 2 Parepare pun memberikan target minimal kepada peserta didik sebanyak 5 juz dari awal di tambah 1 juz dari akhir bagian Alquran. Namun kenyataannya adalah tidak semua peserta didik yang memiliki hafalan Alquran tinggi memiliki prestasi yang bagus atau

7 Unang Wahidin. 2012. Budaya Gemar Membaca Sejak Usia Dini. Edukasi Islami: Jurnal Pendidikan Islam. 1 (01). h.. 57.

${ }^{8}$ Didin Saefuddin Buchori. 2012. Metodologi Studi Islam. Tangrang Selatan: Serat Alam Media. h.. 27.

9 Kementerian Agama Republik Indonesia. 2013. Al Qur'an dan Terjemahnya. Bandung: Nuurun 'Aalim. h. 87 
sebaliknya tidak semua peserta didik yang memiliki prestasi bagus memiliki hafalan yang tinggi.

\section{Permasalahan}

Permasalahan sekarang di madrasah adalah prestasi belajar peserta didik pada bidang ilmu keagamaan. Salah satu strategi pembelajaran di madrasah yakni strategi hafalan, maka memungkinkan ada relasi dengan hasil belajar bidang studi di madrasah. Penelitian ini menfokuskan kajian dalam rumusan masalah, yaitu adakah pengaruh hafalan Alquran terhadap prestasi belajar pada Mata Pelajaran Alquran Hadits di Kelas XI MIA.1MAN 2 Parepare?

\section{METODE PENELITIAN}

Sugiyono menyatakan bahwa populasi merupakan keseluruhan obyek atau subyek yang berkualitas dan berkarakteristik yang akan dipelajari oleh peneliti untuk mendapatkan kesimpulan. Populasi penelitian berjumlah 23 orang peserta didikKelas XI MIA.1 MAN 2 Parepare. Sampel merupakan bagian obyek atau subyek dari populasi. Apabila populasi relatif kecil (kurang dari 30) maka teknik sampel yang digunakan adalah sampling jenuh. Istilah lain untuk penentuan teknik pengambilan sampel ini adalah sensus. ${ }^{10}$ Sampel penelitian adalah seluruh peserta didikdan siswi Kelas XI MIA.1 MAN 2 Parepare sebanyak 23 orang.

Pengumpulan data dilakukan dengan menggunakan angket atau kuesioner, wawancara, observasi, dan dokumentasi. Instrumen penelitian, dalam penelitian ini dilakukan dengan menggunakan angket (untuk variabel X) dan nilai akhir tahun (untuk variabel Y). Pengujian instrumen menggunakan uji validitas dan uji realibilitas. Instrumen valid jika dapat mengukur apa yang diharapkan dan dapat menjelaskan data dari variabel penelitian secara tepat. ${ }^{11}$ Sedangkan instrumen yang reliabel jika instrumen tersebut ketika digunakan beberapa kali dapat mengukur obyek yang sama, sehingga data yang diperoleh sama. ${ }^{12}$

${ }^{10}$ Sugiyono. Metode Penelitian Kuntitatif, Kualitatif, $R \& D$, h.. 215.

${ }^{11}$ Sugiyono. Metode Penelitian Kuntitatif, Kualitatif, $R \& D$. h.. 348.

${ }^{12}$ Sugiyono. Metode Penelitian Kuntitatif, Kualitatif, R\&D. h..348. 
Dalam penelitian digunakan pendekatan metode kuantitatif dengan analisis data deskriptif yang berupa mean, median, modus, tabel distribusi, histogram, dan tabulating. Sedangkan uji prasyarat analisis menggunakan uji normalitas dengan uji liliefors.

\section{HASIL PENELITIAN}

Instrument penelitian dalam bentuk angket dibagikan kepada responden kemudian dianalisis dan diolah secara statistic. Berikut hasil pengujiannya, yaitu:

Tabel 1

Hsil Uji Normalitas

\begin{tabular}{|c|c|c|c|}
\hline Variabel & $L_{0}$ & Kondisi & Keterangan \\
\hline Hafalan Al-Qur'an & 0,1207 & $L_{0}$ & Normal \\
& & 0,18 & \\
\hline Prestasi Belajar & 0,1613 & $L_{0}$ & Normal \\
& & 0,18 & \\
\hline
\end{tabular}

Sumber: Data primer diolah

Pengujian hipotesis menggunakan analisis regresi linear sederhana dengan menggunakan korelasi product moment. Berikut ini cara perhitungannya, yaitu:

Tabel 2

Perhitungan Koefisien Korelasi

\begin{tabular}{|c|c|c|c|c|c|}
\hline $\begin{array}{c}\text { No. } \\
\text { Responden }\end{array}$ & $\mathrm{X}$ & $\mathrm{Y}$ & $\mathrm{XY}$ & $\mathrm{X}^{\mathbf{2}}$ & $\mathrm{Y}^{\mathbf{2}}$ \\
\hline 1 & 78 & 90 & 7020 & 6084 & 8100 \\
\hline 2 & 78 & 88 & 6864 & 6084 & 7744 \\
\hline 3 & 56 & 70 & 3920 & 3136 & 4900 \\
\hline 4 & 78 & 87 & 6786 & 6084 & 7569 \\
\hline 5 & 73 & 84 & 6132 & 5329 & 7056 \\
\hline 6 & 78 & 80 & 6240 & 6084 & 6400 \\
\hline 7 & 77 & 82 & 6314 & 5929 & 6724 \\
\hline 8 & 78 & 79 & 6162 & 6084 & 6241 \\
\hline 9 & 78 & 94 & 7332 & 6084 & 8836 \\
\hline
\end{tabular}




\begin{tabular}{|c|c|c|c|c|c|}
10 & 78 & 90 & 7020 & 6084 & 8100 \\
\hline 11 & 67 & 82 & 5494 & 4489 & 6724 \\
\hline 12 & 85 & 84 & 7140 & 7225 & 7056 \\
\hline 13 & 77 & 85 & 6545 & 5929 & 7225 \\
\hline 14 & 78 & 88 & 6864 & 6084 & 7744 \\
\hline 15 & 77 & 90 & 6930 & 5929 & 8100 \\
\hline 16 & 77 & 90 & 6930 & 5929 & 8100 \\
\hline 17 & 74 & 82 & 6068 & 5476 & 6724 \\
\hline 18 & 77 & 94 & 7238 & 5929 & 8836 \\
\hline 19 & 77 & 90 & 6930 & 5929 & 8100 \\
\hline 20 & 77 & 90 & 6930 & 5929 & 8100 \\
\hline 21 & 77 & 90 & 6930 & 5929 & 8100 \\
\hline 22 & 73 & 84 & 6132 & 5329 & 7056 \\
\hline 23 & 78 & 90 & 7020 & 6084 & 8100 \\
\hline JUMLAH & 1746 & 1983 & 15094 & 13317 & \multirow{2}{*}{171635} \\
\hline
\end{tabular}

Dari tabel di atas diketahui data sebagai berikut:

$$
N=23 \quad \sum X Y=150,941
$$

$\sum X=1746 \quad \sum X^{2}=133,172$

$\sum Y=1983 \quad \sum Y^{2}=171,635$

$$
r_{x y}=\frac{N \Sigma X Y-(\Sigma X)(\Sigma Y)}{\sqrt{\left(23 x 133,172-\left(1.746^{2}\right) x\left(23 x 171.635-\left(1.983^{2}\right)\right.\right.}}
$$

Dari hasil perhitungan menunjukkan bahwa nilai $\mathrm{r}$ hitung terletak diantara $0,60-0,799$, sehingga nilai koefisien korelasinya berkategori kuat dengan nilai 0,6270. Sedangkan pengujian signifikansi koefisien korelasi menggunakan uji-t diperoleh nilai sebesar 3,689. Berikut perhitungannya:

Dari hasil perhitungan menunjukkan bahwa nilai $r$ hitung terletak diantara 0,60-0,799, sehingga nilai koefisien korelasinya berkategori kuat dengan nilai 0,6270. Sedangkan pengujian signifikansi koefisien korelasi menggunakan uji-t diperoleh nilai sebesar 3,689. Berikut perhitungannya: 


$$
\begin{gathered}
t=\frac{r \sqrt{n-2}}{\sqrt{1-r^{2}}} \\
t=\frac{0,6270 \sqrt{23-2}}{\sqrt{1-0,6270^{2}}} \\
t=3,689
\end{gathered}
$$

Adapun signifikansi yang digunakan sebesar 5\% sehingga diperoleh nilai t tabel sebesar 2,080. Hasil ini menunjukkan bahwa t hitung lebih besar dari t tabel $(3,689$ 2,080) sehingga dapat disimpulkan bahwa H0 ditolak dan Ha dimana terdapat hubungan yang positif antara hafalan Alquran dengan prestasi belajar peserta didik di kelas XI MIA.1MAN 2 Parepare. Untuk mengetahui tingkat ketepatan garis regresi digunakan koefisien determinasi. Garis regresi digunakan untuk menjelaskan proporsi dari ragam variabel bebas yang menerangkan variabel terikatnya. Adapun nilai r2 adalah sebesar 0,3932. Artinya bahwa nilai tersebut menunjukkan variabel prestasi belajar peserta didik MAN 2 Parepare pada kelas XI MIA.1 dapat ditentukan oleh variabel hafalan Alquran 39,32\%.

\section{PEMBAHASAN}

Hasil penelitian ini di uji dengan menggunakan korelasi product moment pada taraf signifikansi 5\%. Hasil perhitungan diperoleh $\mathrm{r}$ hitung sebesar 0,6270 dan $r$ tabel sebesar 0,4114 sehingga koefisien korelasi yang dihasilkan termasuk kategori kuat bernilai positif. Untuk pengujian signifikansi koefisien korelasi menggunakan uji-t diperoleh nilai sebesar 3,689 signifikansi yang digunakan sebesar 5\% sehingga diperoleh nilai t tabel sebesar 2,080. Hasil ini menunjukkan bahwa t hitung lebih besar dari t tabel $(3,689>2,080)$. Koefisien determinan atau besarnya sumbangan pengaruh variabel X terhadap Y adalah 0,3932 atau 39,32\%.

Disiplin ilmu keagamaan (Islam) semuanya bermuara kepada sumber primer Islam, yakni Alquran. Penguasaan atau hafalan Alquran menjadi instrument kuat dalam mengkaji disiplin ilmu dalam rumpun Islam. Hafalan Alquran bagi peserta didik memiliki relevansi dengan mata pelajaran lain yang dapat memicu bagi penguasaan beberapa materi ajar. Penguasaan materi ajar melalui kemampuan hafalan Alquran berpengaruh signifikan kepada prestasi belajar. Indikator prestasi belajar di sini 
menekankan pada aspek minat, motivasi, keaktifan, dan nilai hasil belajar peserta didik.

Materi pelajaran Alquran Hadis memerlukan kemampuan dasar dan landasan kajian yang berasal dari ayat-ayat Alquran dan Hadis. Peserta didik yang memiliki hafalan Alquran tinggi, pembelajaran Alquran Hadis dapat berjalan efektif dan efisien. Pendidik berorientasi pada pembelajaran Alquran Hadis yaitu agar peserta didik menghafal ayat-ayat Alquran dan Hadis berdasarkan materi yang diajarkan dan sekaligus diamalkan dalam kehidupan kesehariannya. Melalui penguasaan dan hafalan ayat-ayat Alquran, pendidik semakin inovatif dan kreatif dan peserta didik menjadi senang dan gembira dalam mengikuti pembelajaran.

\section{KESIMPULAN}

Kesimpulan dari hasil penelitan adalah H0 ditolak dan Ha diterima, yaitu terdapat hubungan positif antara hafalan Alquran terhadap prestasi belajar peserta didik kelas XI MIA.1MAN 2 Parepare yang ditunjukkan dengan $\mathrm{t}$ hitung lebih besar dari $\mathrm{t}$ tabel $(3,689$ 2,080). Pentingnya menggunakan strategi hafalan dapat berimplikasi kepada penguatan ketiga ranah yaitu kognitif, afektif, dan psikomotorik. Semakin tinggi kemampuan hafalan peserta didik, semakin efektif dan efisien pembelajaran Alquran Hadis di kelas. pembelajaran Alquran Hadis yang efektif dan efisien, berimplikasi kepada pendidik yang lebih kreatif dan inovatif, dan peserta didik menjadi aktif dan senang. Hal tersebut menegaskan pentingnya MAN 1 Parepare mengembangkan strategi hafalan ayat-ayat Alquran sebagai instrument efektivitas dan efisiensi pembelajaran serta sekaligus membantu pendidik dan peserta didik mengikuti pembelajaran yang menyenangkan.

\section{DAFTAR PUSTAKA}

Al-Qattan, M. Khasil. 2013. Studi Ilmu-Ilmu Al-Qur'an. Pent:Mudzakir. Surabaya: Halim Jaya.

Alwi, H. 2003. Kamus Besar Bahasa Indonesia Edisi III. Jakarta: Balai Pustaka.

Anonimus. Manfaat Menghafal Al Quran Ternyata Bisa Meningkatkan Prestasi Belajar di Sekolah. 
(http://[www.1001hafizh.org/blog/?p=115, diakses pada 3 April 2018 jam 20.15).

Arifin, Z. 2011. Evaluasi Instruksional: Prinsip-Teknik-Prosedur. Bandung: Remaja Rosdakarya.

Arikunto, S. 2006. Prosedur Penelitian Suatu Pendekatan Sistem. Jakarta: Rineka Cipta.

Arikunto, S. 2008. Dasar-dasar Evaluasi Pendidikan. Jakarta: Bumi Aksara.

Asmani, J.M. 2011. 7 Tips Aplikasi Pakem. Jogjakarta: DIVA Press Anggota [KAPI].

Bartolomeus, S. 2013. Visi Pendidikan Ki Hajar Dewantara. Yogyakarta: Kanisius.

Buchori, D.S. 2012. Metodologi Studi Islam. Tanggerang Selatan: Serat Alam Media.

Chalil, M. 2011. Al Quran dari Masa ke Masa. t.k. Ramadhani.

Dariyo, A. 2013. Dasar-dasar Pedagogi Modern. Jakarta: PT Indeks Permata Puri Media.

Departemen Agama RI. 2016. Pedoman Umum Pengembangan Silabus Madrasah Ibtidaiyah. Jakarta: Direktorat Jenderal Kelembagaan Agama Islam.

Hadi, S. 2004. Analisis Regresi. Yogyakarta:Penerbit Andi.

Halik, Abdul, Ahdar, Suredah. 2018. "The Influence of Emotional and Spiritual Intelligence of Educator towards Learning Quality Improvement", Proceeding $5^{\text {th }}$ International Conference on Applied Sciences, Arts and Social, and Community Development in the ASEAN 2018, University of the Philippines, Manila, July 19-20.

Hanafie Das, St. Wardah, Abdul Halik, Zulfianah, Muh Naim. 2018. "Strategies of Islamic Education Teachers to Increase Students' Interest in Learning and Practicing in State Junior High School (SMPN) 1 Lanrisang, Pinrang", Madania, Vol. 22, No. 2, Desember 2018. 
Hery, BAI. 2013. Agar Orang Sibuk Bisa Menghafal Al Qur'an. Yogyakarta: Pro- U Media.

Kementerian Agama Republik Indonesia. (2013). Al Qur'an dan Terjemahnya. Bandung: Nuurun 'Aalim.

Komariyah, I. 2012. Belajar dan Pembelajaran. Yogyakarta: Teras.

Maunah, B. 2009. Metodologi Pengajaran Islam. Yogyakarta: Teras.

Muhammad, F. dan Sulistyiorini. 2012. Belajar dan Pembelajaran, Meningkatkan Mutu Pembelajaran Sesuai Standar Nasional. Yogyakarta: Teras.

Munawwir, A.W. 1997. Kamus Al Munawwir Arab-Indonesia Terlengkap. Surabaya: Pustaka Progressif. hlm. 249.

Poerwadarminta, WJS. 2002. Kamus Besar bahasa Indonesia. Jakarta: Duta Rakyat.

Qoyyum, A. 2009. Keajaiban Hafalan, Bimbingan bagi yang Ingin Menghafal Al Qur'an. Jogjakarta: Pustaka Al Haura.

Rauf, AAA. 2009. Kiat Sukses Menjadi Hafizh Qur'an Da'iyah. Bandung: Syamil Cipta Media.

Sa'dulloh. 2008. 9 Cara Praktis Menghafal Al Qur'an. Jakarta: Gema Insani.

Salmeto. 2010. Belajar dan Faktor-Faktor yang Mempengaruhinya. Jakarta: Rineka Cipta.

Soetjipto. 2009. ProfesiKeguruan. Jakarta: PT. Rineka Cipta.

Sudjana, N. 2011. Dasar-dasar Proses Belajar Mengajar. Bandung: Sinar Baru Algesindo.

Sugiyono. 2013. Metode Penelitian Kuantitatif, Kualitatif, dan R\&D. Bandung: AFABETA.

Wahidin, U. 2012. Budaya Gemar Membaca Sejak Usia Dini. Edukasi Islami: Jurnal Pendidikan Islami, 1(01). 56. 
Wahid, W.A. 2013. Cara Cepat Bisa menghafal Al Qur'an. Yoyakarta: Diva Press.

Zakaria, A. 2011. Makna Kembali kepada Al Quran dan As Sunnah. Garut: IBN AZKA multimedia. 